D) Check for updates

Cite this as: $B M J$ 2021;373:n843 http://dx.doi.org/10.1136/bmj.n843 Published: 01 April 2021

\section{Sex, gender, and medical data}

This editorial (BMJ 2021;372:n735, doi:10.1136/bmj.n735) should have specified that the use of odd NHS numbers for male patients and even numbers for female patients applies only in Scotland. This has now been corrected. 